\title{
Erratum to: Double Bond Stereochemistry Influences the Susceptibility of Short-Chain Isoprenoids and Polyprenols to Decomposition by Thermo-Oxidation
}

Ewa Molińska nee Sosińska ${ }^{1} \cdot$ Urszula Klimczak $^{1} \cdot$ Joanna Komaszyło $^{1}$ • Dorota Derewiaka $^{2} \cdot$ Mieczysław Obiedziński $^{2} \cdot$ Magdalena Kania $^{3}$.

Witold Danikiewicz $^{3} \cdot$ Ewa Swiezewska $^{1}$

Published online: 12 April 2015

(C) AOCS 2015

Erratum to: Lipids (2015) 50:359-370

DOI 10.1007/s11745-015-3998-8

In the original publication of the article, the first author's name was published without her complete surname. The correct name should read as "Ewa Molińska nee Sosińska".

The online version of the original article can be found under doi:10.1007/s11745-015-3998-8.

Ewa Molińska nee Sosińska

esosinska@ibb.waw.pl; ewamolinska@tlen.pl

1 Department of Lipid Biochemistry, Institute of Biochemistry and Biophysics, Polish Academy of Sciences, Pawinskiego 5a, 02-106 Warsaw, Poland

2 Faculty of Food Sciences, Warsaw University of Life Sciences, Nowoursynowska 159, 02-776 Warsaw, Poland

3 Laboratory of Mass Spectrometry, Institute of Organic Chemistry, Polish Academy of Sciences, Kasprzaka 44/52, 01-224 Warsaw, Poland 